DOSSIÊ

\title{
Plano estrafégico 2019-2022 para a educação paulista: uma nova morfologia organizacional do trabalho do professor?
}

Strate gic plan 2019-2020 for education in São Paulo: a new organisational morphology of teacher's work?

\section{Breno alves dos santos Blundi* vitória Turati de BarroS ** giovanna candeila Pomaro***}

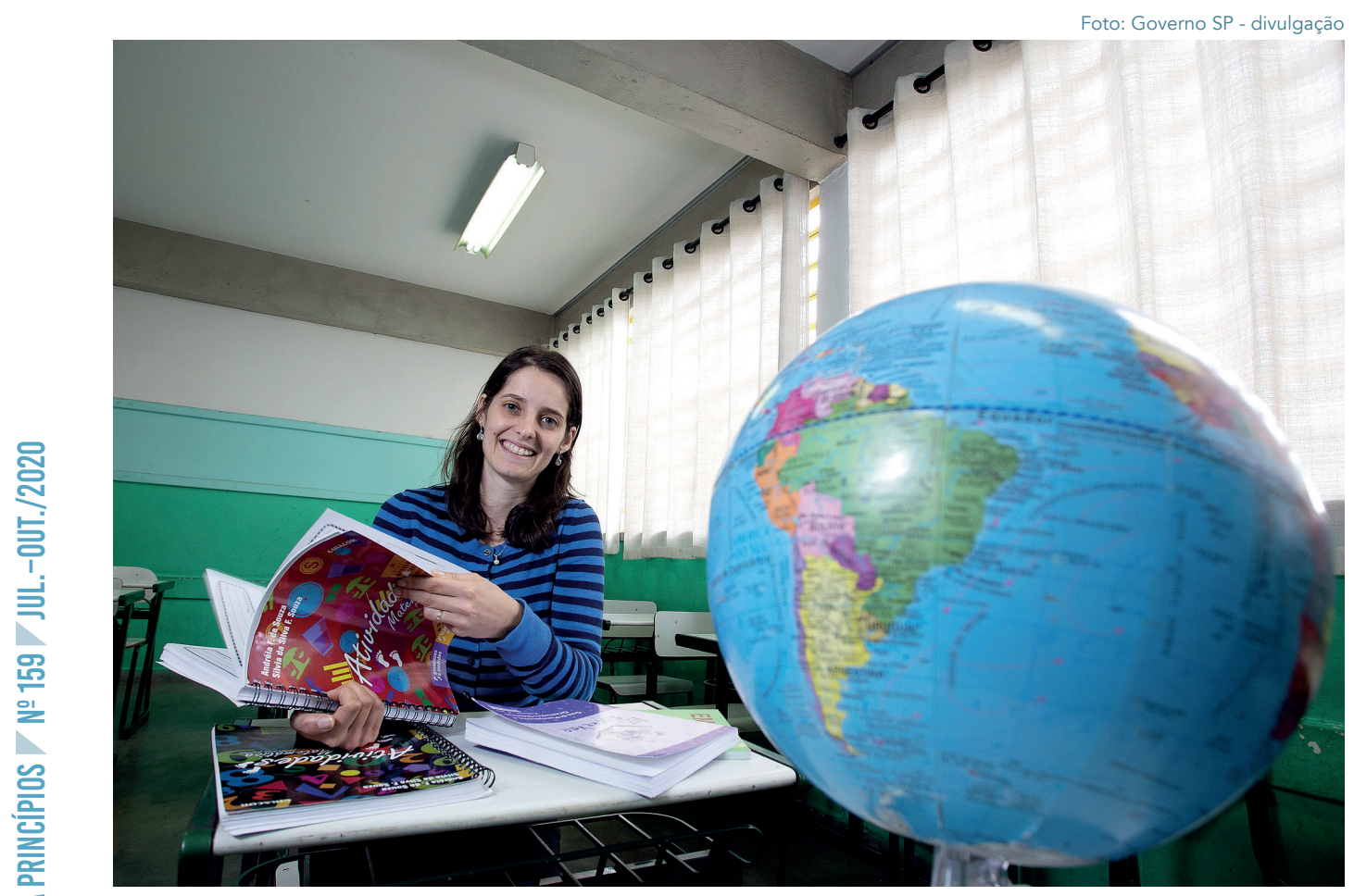

Andréia Fernandes de Souza, 31 anos, professora da Escola Estadual Fúlvio Abramo, na Cidade Tiradentes, localizada no extremo leste de São Paulo 


\section{RESUMO}

O presente artigo apresenta os resultados de uma pesquisa bibliográfica e documental que desenvolvemos tomando como objeto de análise o Plano estratégico 2019-2022: educação para o século XXI, publicado pela Secretaria da Educação do Estado de São Paulo em 3 de julho de 20I9. Mais especificamente, nossa análise tem como objeto central o "Mapa estratégico 2019-2022", o qual foi amplamente divulgado nas escolas da rede estadual de educação básica do estado de São Paulo. A partir da problematização e análise da chamada globalização da economia, do processo de reestruturação produtiva e da nova morfologia do trabalho decorrente das novas formas de organização do trabalho, buscamos responder, por meio da análise do plano estratégico do governo paulista, em que medida essa nova morfologia do mundo do trabalho atinge o trabalho dos professores da educação escolar. Os resultados da pesquisa demonstraram que essa influência existe e que resulta na intensificação da precarização do trabalho do professor na rede da educação básica do estado de São Paulo.

Palavras-chave: Morfologia do trabalho; Capitalismo; Globalização; Educação.

\section{ABSTRACT}

This article shows the results of a bibliographic and documental research that we developed aiming to analyse the Strategic Plan 2019-2022: education for the 2Ist century, published by the Secretariat of Education of São Paulo State on July 3, 2019. More specifically, our analysis has as its central object the "2019-2022 Strategic Map", which was widely spread in the schools of the state basic education network of São Paulo. From the problematisation and analysis of the so-called globalisation of the economy, the process of productive restructuring and the new morphology of labour, coming from the new forms of labour organisation, we seek to answer, through the analysis of the strategic plan of São Paulo's government, to what extent will this new morphology of the labour world reach the work of school education teachers. The results of the survey showed that this influence exists and that it results in intensifying the precariousness of teacher's work in the basic education network of São Paulo state.

Keywords: Morphology of work; Capitalism; Globalization; Education. 


\section{INTRODUCÃ̃̃o}

Desde a crise da sociedade capitalista de I970, um novo léxico passou a ser difundido para explicar e justificar as mudanças econômicas, políticas e sociais: o vocabulário de uma sociedade supostamente mais desenvolvida em função do avanço tecnológico. Desde então, tornou-se lugar comum falar em globalização da economia, qualidade total, novas competências para o mundo do trabalho e revolução tecnológica, entre outras expressões. Contudo, o que esses novos conceitos escondem, em sua essência, é que, para superar a crise e garantir a manutenção do lucro e da acumulação, o capital promoveu como estratégia uma ampla reestruturação em sua forma de organização econômica, política e social. Ou seja, a assim chamada globalização da economia, juntamente com a reestruturação produtiva, mudaram as aparências das relações sociais capitalistas sem tocar na sua contradição fundamental: por um lado, a ampliação da riqueza produzida pelo trabalho humano e apropriada pela classe detentora dos meios de produção da vida, e, ao mesmo tempo, o aprofundamento da miséria da classe que a produz.

Nessa perspectiva, para garantir seus objetivos de acumulação, o capital passou a divulgar esse novo léxico, essa novilíngua ${ }^{1}$, promovendo a construção de um novo consenso social. Para tanto, a educação ocupa um lugar de destaque, tendo em vista que, no Brasil, a partir da década de I990, esse novo vocabulário passou a fundamentar e legitimar a reforma educacional e as políticas educacionais dela decorrentes, com o objetivo de colocar a educação brasileira nos trilhos do século XXI.

Com base nos pressupostos acima mencionados, o presente artigo apresenta os resultados da pesquisa, bibliográfica e documental, que desenvolvemos tomando como objeto de análise o Plano estratégico 20I9-2022: educação para o século XXI, publicado pela Secretaria da Educação do Estado de São Paulo em 3 de julho de 20ı9. Mais especificamente, nossa análise tem como objeto central o "Mapa estratégico 20192022" contido no referido plano, o qual foi amplamente divulgado nas escolas da rede estadual de educação básica do estado de São Paulo (SÃO PAULO, 20I9, p. I5).

Buscamos, portanto, compreender a assim chamada globalização da economia associada ao processo de reestruturação produtiva que, segundo Antunes (20I8), contribuiu para o desenvolvimento de uma nova morfologia do trabalho que trouxe consequências danosas para a classe trabalhadora: subtraindo direitos historicamente conquistados, ampliando o desemprego e precarizando as relações de trabalho e condições de vida dos trabalhadores. No que se refere à educação, buscamos verificar em que medida essa nova morfologia do trabalho afeta o trabalho do professor das escolas públicas do estado de São Paulo por meio da análise das designações contidas no Plano estratégico 2019-2022 do governo estadual paulista.

1 O termo novilíngua é usado aqui em referência à obra de George Orwell intitulada 1984, na qual, segundo Osike (2011, p. 21), "a língua é um instrumento de controle e tem como objetivo limitar o pensamento e impossibilitar o acesso a quaisquer conceitos que difiram dos princípios do Ingsoc". 
As questões que nortearam a pesquisa foram as seguintes: I) A assim chamada globalização da economia pode ser considerada um processo de mundialização do capital? 2) Quais as consequências desse fenômeno para a educação? 3) Como se caracteriza a nova morfologia do trabalho no contexto da reestruturação produtiva e que implicações traz para a classe trabalhadora? 4) A nova morfologia do trabalho atinge o trabalho dos professores?

Para responder a essas questões realizamos a análise do conceito de globalização com base nos trabalhos de Chesnais (I996), Lima (2007), Santos (2002;2005), Germano (2007), Ferreira (2009), Stoer (2002), Pureza (2005), Azevedo (2006) e Dourado (2008). Para compreender a nova morfologia do trabalho, decorrente do processo de reestruturação produtiva, nos apoiamos nos trabalhos de Antunes (1995; 1999; 2005; 2009; 2018), Vasapollo (2005) e Vasapollo e Arriola (2005). As leituras e sistematizações dos estudos desses autores proporcionaram a base teórica necessária para examinarmos o conteúdo do documento intitulado Plano estratégico 2019-2022: educação para o século XXI, elaborado pela Secretaria de Educação do Estado de São Paulo (20I9).

Diante do exposto, esse artigo foi dividido em três seções. Na primeira, apresentamos os resultados dos estudos sobre o conceito de globalização. Na segunda, abordamos o tema da nova morfologia do trabalho decorrente do processo de reestruturação produtiva. Na terceira seção, apresentamos os resultados das análises do Plano estratégico 20I9-2022: educação para o século XXI.

\section{A ASSIM CHAMADA GLOBALIZAÇÃO DA ECONOMIA}

Segundo Chesnais (1996), a chamada globalização da economia, como ficou conhecida pelo discurso dominante, é fruto do processo de internacionalização do capital, o qual o autor denomina "mundialização do capital". Trata-se, segundo esse autor, de uma forma de acumulação predominantemente rentista, caracterizada por uma crescente centralização do capital financeiro. Concordamos com Chesnais (1996) no que se refere ao termo globalização: a chamada globalização da economia se constitui, na verdade, na mundialização do capital, o que significa que o termo globalização propalado pelo discurso dominante tem um caráter puramente ideológico.

Nessa perspectiva, Lima (2007, p. 4I-42) ressalta que o sentido político dado pela ideologia da globalização econômica se caracteriza como um suposto processo de integração mundial, mas que, no entanto, omite que a mesma se articula como:

Um processo de unificação-hierarquização, atravessado pela contradição gerada pelo aprofundamento das desigualdades econômicas que constituem as relações sociais na atualidade. A arquitetura da mundialização do capital tem por objetivo principalmente permitir a valorização, em escala internacional, de um capital de investimento financeiro constituído por uma profunda hierarquização política e econômica, ordenada em torno de três polos da tríade (Estados Unidos, Europa Ocidental e Japão). (Grifos nossos.) 


\section{A educação ocupa \\ lugar estratégico \\ na construção, pelo \\ capital, de um novo \\ consenso social \\ que garanta seus \\ objetivos de lucro e acumulação}

Segundo Santos (2005), a "globalização" é formada por conjuntos diferenciados de relações sociais, que se manifestam em variados fenômenos. Portanto, para compreender seu significado, temos de analisar o fenômeno em seu movimento contraditório, isto é, desde uma perspectiva dialética e como parte da totalidade das relações sociais capitalistas. Ou seja, temos de analisar o fenômeno do ponto de vista do seu movimento hegemônico e contra-hegemônico. Nesse sentido, Santos (2002) diferencia a globalização hegemônica da contra-hegemônica, considerando a primeira predominantemente organizada "de cima para baixo" e regressiva do ponto de vista dos direitos sociais. A segunda, isto é, a contra-hegemônica, visa inverter esse quadro, se organizando da base para o topo. Nesse sentido, a globalização contra-hegemônica é construída por alianças e parcerias transfronteiriças de movimentos sociais, que colocam como foco, em sua luta, a derrubada dos efeitos da globalização neoliberal (hegemônica). Em outras palavras, a globalização contra-hegemônica visa resistir a poderes translocais, nacionais ou até mesmo globais no terreno da luta de classes.

Germano (2007, p. 48), ao se referir à globalização contra-hegemônica, cita os seguintes exemplos:

As lutas em favor da reforma agrária, da demarcação das terras indígenas; contra a devastação da floresta amazônica, a poluição ambiental, a precarização do trabalho, a erosão dos direitos sociais, o tráfico de pessoas, as guerras e a intolerância; bem como as lutas em defesa das diversas tradições da criatividade e dos diferentes sistemas de conhecimento, como faz Vandanna Shiva na Índia, são exemplos de lutas locais contra poderes translocais/ globais. Tais lutas se traduzem em ações e políticas emancipatórias que se distanciam das políticas compensatórias e residuais, no sentido atribuído por Richard Titmuss, bem como das políticas emergenciais, focalizadas e assistencialistas do neoliberalismo. Enfim, das políticas de "pronto socorro social”, de que fala Castel (1997). Essas políticas levam oxigênio a quem está em desespero, mas mantém a exclusão e a subalternidade, reforçando uma ordem social desigual, injusta e opressiva. 
Para Ferreira (2009), o termo globalização revela a crescente e contínua interdependência mundial nos planos econômico, político e cultural. Desse modo, complementando os escritos de Ferreira (2009), Dale (200I) explica que:

É frequentemente considerada como representando um inelutável progresso no sentido da homogeneidade em algo parecido, como um conjunto de forças que estão a tornar os estados-nação obsoletos e que pode resultar em algo parecido com uma política mundial, e como refletindo o crescimento irreversível da tecnologia da informação (DALE, 200I, p. I34).

Dessa forma, Lima (2007, p. I84) complementa que a globalização econômica não alcança a:

Homogeneização do espaço, porque a acumulação do capital ocorre em ritmos desiguais de tempo e realiza-se por meio das profundas desigualdades de concentração da produção e do consumo da estrutura técnico-produtiva em determinadas regiões e países, em detrimento de outras áreas do espaço mundial. Ou seja, no espaço convivem tempos desiguais e estruturas técnicas diferenciadas. As inovações tecnológicas não alcançam todos os países e regiões, apenas aqueles de interesse do capital.

Para Ferreira (2009, p. 57), esse novo e atualizado dinamismo constitui-se de um novo campo de disputa por hegemonia entre "diversos atores e organismos dos países dominantes, países semiperiféricos, periféricos e vem permitindo gerar profundas transformações econômicas e políticas em escala planetária”. Nessa perspectiva, para Santos (2005, p. 35), essa nova economia mundial, gerada neste novo cenário, passou a se manifestar como uma:

Economia dominada pelo sistema financeiro e pelo investimento à escala global; processos de produção flexíveis e multilocais; baixos custos de transporte; revolução nas tecnologias de informação e de comunicação; desregulação das economias nacionais; proeminência das agências financeiras multilaterais; emergência de três grandes capitalismos transnacionais: o americano, baseado nos EUA e nas relações privilegiadas deste país com o Canadá, o México e América Latina; o japonês, baseado no Japão e nas suas relações privilegiadas com os quatro pequenos tigres e com o resto da Ásia; e o europeu, baseado na União Europeia e nas relações privilegiadas desta com a Europa do Leste e com o Norte da África.

Ferreira (2009, p. 57) ressalta que tais mudanças decorrem da:

Naturalização do consenso hegemônico neoliberal, forjado pelos países dominantes, de que o único modelo de desenvolvimento possível é orientado para o e pelo mercado, fato que vem exigindo mudanças estruturais e políticas de ajustamento macroeconômicas. 
Tais mudanças, realizadas por parte dos Estados para se conciliarem às novas regras do mercado mundial, devem priorizar:

A economia de exportação; as políticas monetárias e fiscais devem ser orientadas para a redução da inflação e da dívida pública e para a vigilância sobre a balança de pagamentos; os direitos de propriedade privada devem ser claros e invioláveis; o setor empresarial do Estado deve ser privatizado; a tomada de decisão privada, apoiada por preços estáveis, deve ditar os padrões nacionais de especialização, a mobilidade dos recursos, dos investimentos e dos lucros; a regulação estatal da economia deve ser mínima; deve reduzir-se o peso das políticas sociais no orçamento do Estado, reduzindo o montante das transferências sociais, eliminando a sua universalidade e transformando-as em meras medidas compensatórias em relação aos estratos sociais inequivocamente vulnerabilizados pela atuação do mercado (SANTOS, 2005, p. 35).

Nesse cenário, a globalização política, segundo Ferreira (2009), vem impondo, cada vez mais, novas relações de poder através das novas articulações entre fronteiras e de práticas transnacionais. Desse modo, o Estado-nação perde o seu domínio na regulação das funções política, social e econômica, ganhando "importância a sociedade civil e a presença decisiva das agências financeiras e dos diversos atores transnacionais, como as grandes empresas multinacionais" (FERREIRA, 2009, p. 58).

Nessa lógica, Santos (2005), referindo-se ao trabalho de Bob Jessop, explica quais são as três tendências de transformação do poder do Estado na América do Norte e na Europa, se configurando em:

a) desnacionalização do Estado: quando ocorre um certo esvaziamento do aparelho do Estado nacional, que decorre da reorganização de velhas e novas capacidades do Estado, tanto territorial como funcionalmente, em níveis subnacional e supranacional;

b) desestatização dos regimes políticos: está retratada na transição do conceito de governo (government) para governação (governance), ou seja, de um modelo de regulação social e econômica assentada no Estado para um que se assente em parcerias privadas ou associações entre organizações governamentais, não governamentais e para governamentais, nas quais se coloca como papel para o Estado apenas a tarefa de coordenação;

c) internacionalização do Estado nacional: manifesta-se no aumento do impacto estratégico do contexto da atuação internacional do Estado, o que acaba por envolver a expansão do campo de atuação e ação do Estado nacional na adequação (sempre que necessária) das condições internas às exigências extraterritoriais ou transnacionais.

Stoer (2002) explica a diferença entre o modelo econômico internacional e o modelo econômico global. Nesse sentido, afirma que, no modelo de economia inter- 
nacional, os países possuíam um importante grau de controle sobre as suas próprias economias nacionais e podiam regular, da forma que entendessem melhor, a sua relação com a economia mundial, enquanto no modelo de economia global emergente a capacidade de autonomia dos Estados tem sido reduzida para todos, embora em maior grau para alguns. Portanto, paulatinamente, os Estados têm seus papéis reduzidos para ajustar as economias nacionais às dinâmicas e à reestruturação da economia global completamente desregulada.

Nesse sentido, o processo de globalização se torna um ato político determinado pelos Estados-nação dominantes, como estratégia para sair da crise e dar continuidade ao processo de acumulação do capital. Assim, os Estados cedem parte de sua autonomia aspirando à defesa de seus próprios interesses e, ao mesmo tempo, protegendo-se dos efeitos negativos da globalização, buscam desfrutar de suas vantagens.

Com esse panorama, as organizações internacionais tornam-se as protagonistas principais em lugar dos Estados-nação. Entre essas organizações, assumem papel de destaque: a Organização das Nações Unidas (ONU); o Banco Mundial (BM); a Organização para a Cooperação e Desenvolvimento Econômico (OCDE); o Fundo Monetário Internacional (FMI); e a Organização Mundial do Comércio (OMC). Além dessas, passam a assumir lugar privilegiado as organizações regionais, como: a União Europeia (UE); o Fórum de Cooperação Econômica da Ásia-Pacífico (Apec); e a Associação Norte-Americana de Comércio Livre (Nafta). Tais organizações começam a operar como "atores supranacionais mediante os acordos multilaterais entre os Estados-nação, possibilitando a mediação dos avanços da globalização e dos seus efeitos para os países-membros" (FERREIRA, 2009, p. 59).

Pureza (2005, p. 240) complementa que "a concepção neoliberal da governação global é o complemento dessa destruição seletiva”, ou seja, com o recuo do Estado, ele próprio passa a ter de "intervir para deixar de intervir, ou seja, tem de regular a sua própria desregulação" (SANTOS, 2005, p. 45). Dale (200I, p. II2) complementa que "os mercados são inteiramente dependentes de uma série de condições que só podem ser propiciadas pelo Estado como o detentor do monopólio do controle e sanções legais".

Para Azevedo (2006), a União Europeia pode ser considerada um Estado transnacional, compondo-se em um singular processo de redução de poder e autonomia dos Estados-nação. Assim sendo, podemos afirmar que a importância da UE como entidade reguladora:

Resulta de os seus poderes irem para além dos de qualquer outra organização internacional, uma vez que pode produzir legislação aplicável no interior dos Estados-membros sem necessidade de negociação ou intervenção posterior por parte destes. O direito comunitário representa hoje um dos mais significativos regimes estabelecidos para gerir áreas de ação transnacional. Os Estados deixam, assim, de constituir os únicos centros de poder político dentro dos limites do seu território (GONÇALVES, 2005, p. 34I). 
Nesse cenário de novas relações de poder, Pureza (2005) destaca a naturalização da chamada governação global, que se caracteriza por um "conceito neutro" no discurso dos ideólogos neoliberais e se concretiza na afirmação de redes internacionais: entre governos, organizações internacionais, atores privados e organizações não governamentais transnacionais. Isto é, esses ideólogos disseminam suas ideias como não sendo de nenhum cunho ideológico. Nessa perspectiva, a reconfiguração do Estado exige novas formas de atuação de suas funções de regulação; mais tradicionais, de integração, coesão e de controle social, pois uma vez que ele passa a integrar-se em rede, passa também a assumir papel de articulador e mediador, tanto no nível subnacional como no supranacional.

Portanto, a internacionalização acaba se caracterizando como um modo de reorganizar o poder do Estado, uma vez que "o processo de globalização vem acirrando a competitividade entre os Estados nacionais pela busca da hegemonia" (FERREIRA, 2009, p. 60). Ferreira (2009) complementa que, nessa nova redefinição de poderes, a UE busca ser referência mundial em termos de boas práticas para governança, governança essa que é definida com os documentos produzidos pela União Europeia, tal como o documento da Comissão das Comunidades Europeias - CCE (200I) o qual se constitui em um conjunto de regras, processo e práticas que determinam a qualidade do exercício do poder da UE, sobretudo no que se refere "à responsabilidade, transparência, coerência, eficiência e eficácia" (CCE, 200I).

Ferreira (2009, p. 6I), Seixas (200I) e Dale (2005) utilizam a expressão esvaziamento do Estado para explicar que "um conjunto de suas tradicionais responsabilidades e poderes foram direcionados ou transferidos para o plano supranacional, plano subnacional e para a sociedade civil". Desse modo, a chamada boa governação acaba legitimando as novas formas de atuação do Estado.

Nesse sentido o Estado, ao assumir sua nova função determinada pelo capital, passa a atuar como mediador das relações na sociedade civil. Tais relações se concretizam por meio de contratos, alianças, consórcios com instituições do setor público, com as chamadas organizações não governamentais, mas financiadas com dinheiro público, e com organizações do setor privado. Nesse sentido, Ferreira (2009) afirma que, no âmbito da educação, a busca pela resolução dos problemas dos sistemas nacionais da educação está diretamente relacionada com a nova (des)ordem mundial.

Para Dourado (2008), é nesse contexto de globalização econômica que as mudanças sociais são aprofundadas pela crescente diferenciação do:

Ambiente geopolítico e por expressivo e desigual avanço tecnológico que se efetivam alterações no mundo do trabalho e da produção, as quais, por seu turno, redimensionam as esferas da atividade humana. Estabelece-se, portanto, um espaço contraditório, em que se generalizam e desenvolvem tecnologias favoráveis à integração e, paradoxalmente, a novas formas de inclusão dependente. Tal processo não é resultante, em si mesmo, do avanço tecnológico, mas sim das novas formas de acomodação histórica do modo 


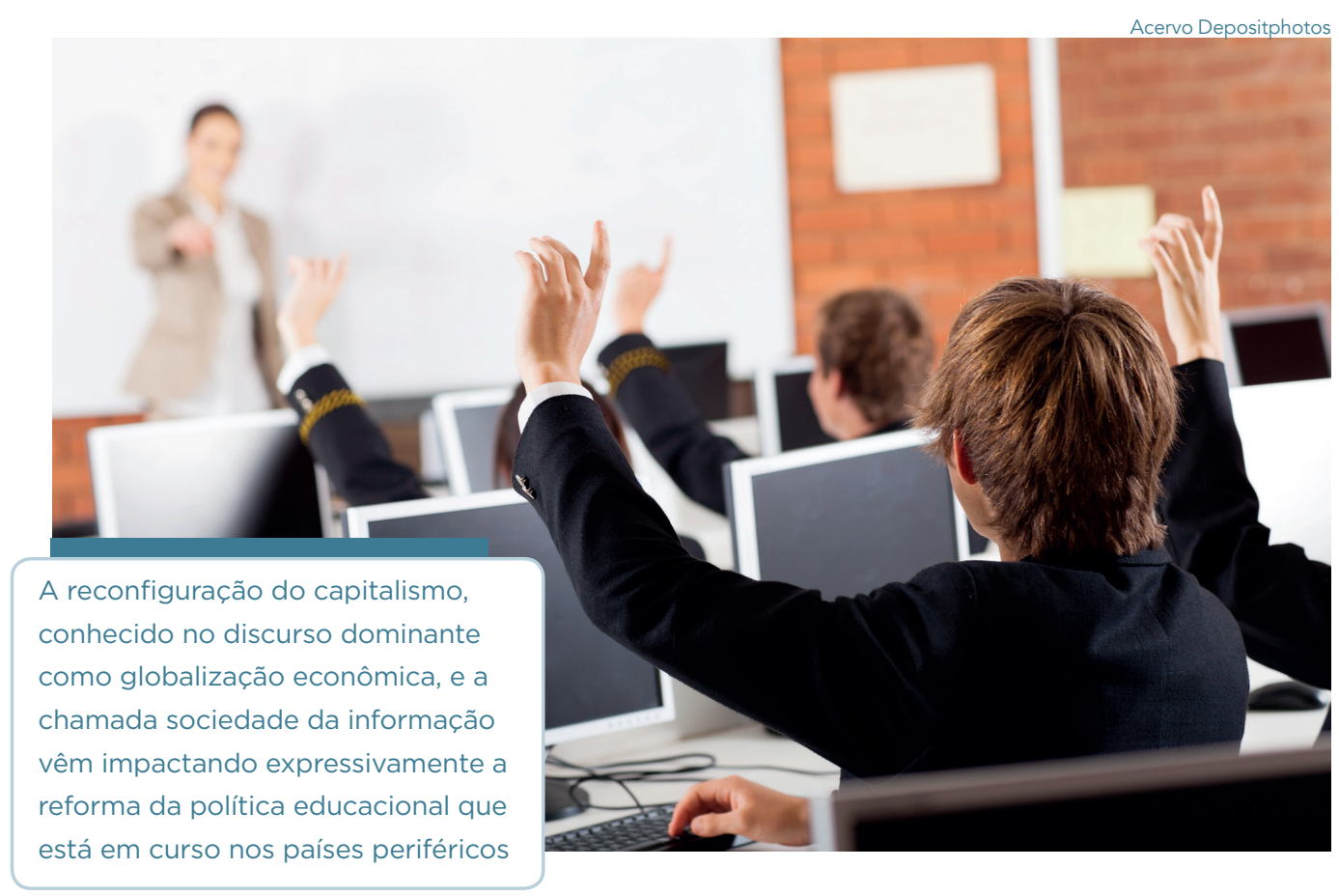

de produção capitalista que alteram as forças de sociabilidade e, consequentemente, a relação entre as forças sociais, que, sob a hegemonia do ethos privado, sofrem a influência das tecnologias eletrônicas, informáticas e cibernéticas (DOURADO, 2008, p. 893, grifos do autor).

A reconfiguração do capitalismo, conhecido no discurso dominante como globalização econômica, e a chamada sociedade da informação vêm, segundo Ferreira (2009), impactando expressivamente a reforma da política educacional que está em curso nos países periféricos. Desse modo, a educação escolar nos países periféricos se constitui como uma

Política internacional de segurança do capital; como promissora área de investimentos para o capital em crise em sua incessante busca por novos mercados e novos campos de exploração lucrativa; e como importante estratégia de difusão da concepção de mundo burguesa (LIMA, 2007, p. 22).

Os estudos dos autores aqui referenciados contribuíram para responder às duas primeiras questões norteadoras da nossa pesquisa: A assim chamada globalização da economia pode ser considerada um processo de mundialização do capital? Quais as consequências desse fenômeno para a educação? Ou seja, foi possível constatar que a assim chamada globalização da economia se constitui na ideologia dominante, que tem por objetivo ocultar a real essência das estratégias de reestruturação do capital em escala planetária, revelando, portanto, que se trata de um processo de mundialização do capital. No que se refere à segunda questão, isto é, às consequências do fenômeno 


\section{Podem-se destacar algumas formas e tipologias de flexibilização: de horário, salarial, organizativa, de cargos, de intensidade de dedicação etc.}

da mundialização do capital para a educação, verificamos que a educação ocupa lugar estratégico na construção, pelo capital, de um novo consenso social que garanta seus objetivos de lucro e acumulação. Podemos afirmar, com base nos trabalhos desses autores, que o novo léxico capitalista contribui, de fato, para a difusão de um novo senso comum, o qual é divulgado por meio dos documentos que passaram a regulamentar a reforma educacional. Portanto, sob o manto da ideologia do determinismo tecnológico, difunde-se, por meio da educação, que estamos vivendo em uma "nova sociedade", a assim chamada sociedade da informação.

\section{O PROCESSO DE REESTRUTURAÇÃO PRODUTIVA E A NOVA MORFOLOGIA DO MUNDO DO TRABALHO}

Vimos na seção anterior que, a partir do início dos anos 1970, o capital implementou globalmente um processo de reestruturação produtiva, visando à recuperação do padrão de sua acumulação e à restituição da hegemonia que perdera no espaço produtivo. $\mathrm{O}$ capital viu, na reestruturação produtiva, a saída de uma de suas crises cíclicas, caracterizada pela superprodução e pela consequente queda nas taxas de lucro e acumulação. Foi nesse contexto que o capital redesenhou, em escala global, velhas e novas modalidades de trabalho, objetivando a recuperação das formas econômicas, ideológicas e políticas de dominação e intensificação da exploração da força de trabalho constituída pela classe trabalhadora.

A reestruturação produtiva se caracteriza por novas formas de organização do trabalho na produção. Ou seja, a crise capitalista dos anos 1970 põe em xeque o modelo taylorista-fordista de organização do sistema fabril, o qual era baseado na produção em massa, no trabalho monótono e repetitivo das esteiras rolantes e na disciplina rígida dos postos de trabalho. Em seu lugar, novas formas de organização do sistema produtivo baseadas no modelo japonês de produção, que ficou conhecido como toyotismo, promovem a reengenharia do processo produtivo. $\mathrm{O}$ toyotismo se caracteriza pela produção após a demanda, pela redução de estoques, pelo trabalho em equipe, pela flexibilização das relações de trabalho, pelo enxugamento dos postos de trabalho e pela terceirização. Esse novo modelo de produção garante ao capital o aumento da produção às custas da intensificação do controle e da exploração da força de trabalho. Trata-se de um modelo de produção que promove a precarização do trabalho, que no léxico empresarial se traduz por meio de conceitos como “'empresa 
enxuta', 'empreendedorismo', 'cooperativismo', 'trabalho voluntário"' (ANTUNES, 2009, p. 49). De acordo com Antunes (2009), houve ainda uma apropriação linguística pelo capital de expressões que estiveram presentes nos movimentos sociais iniciados nos anos I960, tais como "participação social" e "autonomia", visando "dar-lhes outras configurações, muito distintas, de modo a incorporar elementos do discurso operário, porém sob clara concepção burguesa" (ANTUNES, 2009, p. 49, grifos do autor).

Vasapollo (2005), ao analisar essa nova forma de acumulação capitalista e, mais especificamente, o fenômeno do "empreendedorismo", exprime que as vertentes do empreendedorismo se configuram, cada vez mais, como formas ocultas de trabalho assalariado, precarizado, subordinado e instável. Sobretudo se caracterizando como um novo trabalho "autônomo" que, por sua vez, mascara a realidade da redução do ciclo produtivo e de direitos, tratando-se na verdade de uma nova vertente da marginalização social e não de um novo tipo de empresariado, como amplamente divulgado pela burguesia proprietária dos meios de produção.

Para Vasapollo e Arriola (2005), a reestruturada e inédita condição de trabalho se desenvolve enquanto o trabalhador perde direitos e garantias sociais, afinal tudo se converte em precariedade. Nesse sentido, o trabalhador em processo de precarização, ou já precarizado, se vê em um caminho que se bifurca entre ser trabalhador ou desempregado. Com isso, é desenvolvido, segundo os autores anteriormente citados, outro fenômeno: a flexibilização.

A flexibilização do trabalho, nessa nova organização das relações capitalistas de produção, não é sinônimo de riqueza, tampouco de mais horas extras para desenvolver outras atividades laborais ou até mesmo de facilidade de ser admitido. A flexibilização, por parte do elo mais frágil, o detentor da força de trabalho, é caracterizada como ausência de garantias, que acaba aumentando a vulnerabilidade e intensificando o fator de risco mais importante para o trabalhador: o desemprego. Nessa relação de força entre o contratado e o contratante, que tem como fio a flexibilização, a força de trabalho que o contratado tem a oferecer é considerada de pouca importância e de barganha retida, pois, sem garantias, seja em relação à renda, ao futuro ou ao cargo, o trabalhador fica à mercê do contratante, que, por sua vez, não o assegura em momentos de desemprego.

Segundo Antunes (2009), podem-se destacar algumas formas e tipologias de flexibilização: de horário, salarial, organizativa, de cargos, de intensidade de dedicação etc. A flexibilização, segundo Antunes (2009), pode ser compreendida como:

Liberdade da empresa para desempregar trabalhadores sem penalidades, quando a produção e as vendas diminuem; liberdade, sempre para a empresa, para reduzir o horário de trabalho ou de recorrer a mais horas de trabalho; possibilidade de pagar salários reais mais baixos do que a paridade de trabalho exige; possibilidade de subdividir a jornada de trabalho em dia e semana segundo as conveniências das empresas, mudando os horários e as características do trabalho (por turno, por escala, em tempo parcial, horário 
flexível etc.), dentre tantas outras formas de precarização da força de trabalho (ANTUNES, 2009, p. 50-5I).

Nessa perspectiva, a flexibilização, segundo Vasapollo (2009), não é a solução para baixar o índice de desempregados, muito pelo contrário; se caracteriza pela imposição de que os contratados aceitem salários mais baixos, em piores condições de trabalho, com jornadas estendidas, com quase nenhum ou, literalmente, nenhum direito trabalhista, assegurando, desse modo, maiores lucros aos proprietários dos meios de produção.

Antes de darmos prosseguimento à explanação sobre a nova morfologia do trabalho, faz-se necessário explicar que corroboramos a opinião de Antunes (2009) quando ele afirma que a classe trabalhadora "compreende a totalidade dos assalariados, homens e mulheres que vivem da venda da sua força de trabalho" (ANTUNES, 2005, p. I43). Nesse sentido, Antunes (1995; 1999) problematiza o conceito de classe trabalhadora, considerando-a a classe-que-vive-do-trabalho. Desse modo, observa que:

No plano mais analítico, podemos acrescentar que a classe-que-vive-do-trabalho incorpora tanto o núcleo central do proletariado industrial, os trabalhadores produtivos que participam diretamente do processo de criação de mais-valia e da valorização do capital que hoje transcende em muito as atividades industriais, dada a ampliação dos setores produtivos nos serviços, como abarca também os trabalhadores improdutivos, que não criam diretamente mais-valia, uma vez que são utilizados como serviço, seja para uso público, como os serviços públicos, seja para uso capitalista. Isso porque os trabalhadores improdutivos, criadores de antivalor no processo de trabalho, vivenciam situações muito aproximadas com aquelas experimentadas pelo conjunto dos trabalhadores produtivos (ANTUNES, 2009, p. 53).

Por essa ótica, a classe trabalhadora é formada por inúmeros indivíduos, desde aqueles que vivem na zona rural e que necessitam vender sua força de trabalho para o grande ruralista em troca de salário ou alimento, ao proletariado precarizado, fruto do trabalho flexível: o proletariado moderno; o infoproletariado (ANTUNES, 20I8); o trabalhador fabril; de serviços e temporário; profissionais que desenvolvem trabalho imaterial, como por exemplo professores e, além de todos esses, também faz parte da classe-que-vive-do-trabalho, os trabalhadores desempregados.

Acerca da nova morfologia do trabalho, Antunes (2009, p. 5I-53) enumera nove grandes tendências de mudanças no mundo do trabalho que atingem, exclusivamente, a classe trabalhadora:

I) os trabalhos industrial, tradicional, fabril e manual, isto é, especializados, frutos do taylorismo e fordismo, hoje dão lugar à formas desregulamentadas de trabalho que acabam por sua vez reduzindo o número de trabalhadores estáveis, detentores de empregos formais; 
2) trabalho terceirizado ou executado por indivíduos que são submetidos a subcontratos e à informalidade;

3) salários femininos 30\%a 40\% inferiores aos masculinos, ainda que para o mesmo cargo;

4) expansão dos assalariados médios no setor de serviços de empresas como Uber e iFood, que possuem como trabalhadores indivíduos que foram expulsos de seus trabalhos devido à desindustrialização e privatizações em massa;

5) desemprego estrutural de jovens que alcançaram a idade de ingresso no mundo do trabalho;

6) exclusão realizada pelo capital dos trabalhadores considerados "idosos", comumente acima de 40 anos, que, uma vez desempregados, caem na marginalização do mundo do trabalho, na precarização e na informalidade;

7) inclusão do trabalho infantil em diversas atividades produtivas para o capital;

8) desenvolvimento do denominado "terceiro setor", isto é, empresas que demonstram preocupações com causas sociais e assistenciais (como ONGs), sem fins lucrativos, mas que se desenvolvem de maneira eficaz à margem do mercado e que mascaram formas precarizadas de trabalho;

9) aceleração do home-office, alavancado pelo desenvolvimento das tecnologias.

Fica evidenciado, por meio dessas nove grandes tendências apontadas pelo autor, que a nova morfologia do mundo do trabalho pós-reestruturação produtiva se baseia em duas grandes vertentes: precarização e desemprego, ambos frutos, principalmente, da tendência de flexibilização do trabalho.

Podemos afirmar, com base nos estudos de Antunes (2009) que está em curso um processo de precarização estrutural do trabalho. Ou seja, as grandes empresas de capital global exigem a queda e o desmonte dos direitos trabalhistas, bem como de toda a legislação protetora do trabalho. Nesse sentido, flexibilizar e derrubar as políticas protetoras do trabalho e do trabalhador significa aumentar intensamente a precarização do trabalhador e sua exploração.

Com base no exposto nesta seção, podemos afirmar que os trabalhos dos autores pesquisados contribuíram para responder à terceira e à quarta questões que orientaram nossa pesquisa: Como se caracteriza a nova morfologia do trabalho no contexto da reestruturação produtiva e que implicações traz para a classe trabalhadora? A nova morfologia do trabalho atinge o trabalho dos professores?

Com relação às características da nova morfologia do trabalho, Antunes (20I8) esclarece que se trata de novas tendências que se consolidam no contexto do capitalismo contemporâneo. A assim chamada flexibilização do trabalho, outro conceito que compõe o novo léxico empresarial na atualidade, promove a precarização e o desemprego, destituindo a classe trabalhadora, ou, para usar a expressão do autor, a classe-que-vive-do-trabalho, dos direitos trabalhistas e sociais fundamentais e historicamente conquistados. 
À quarta questão que impulsionou o desenvolvimento deste estudo - a nova morfologia do trabalho atinge o trabalho dos professores? - , podemos responder afirmativamente. Sim, essa nova morfologia do trabalho atinge os professores, tendo em vista que, de acordo com Antunes (2009), eles constituem aquela parcela da classe trabalhadora formada por trabalhadores improdutivos no capitalismo. Ou seja, não agregam mais valor porque se incluem na categoria dos trabalhadores de serviços, os quais não criam diretamente mais-valia, são criadores de antivalor no processo de trabalho, porém vivenciam situações que se assemelham àquelas vivenciadas pelo conjunto dos trabalhadores produtivos. Para verificar essa influência da nova morfologia do trabalho na vida dos professores, apresentamos na próxima seção os resultados das análises que realizamos do Plano estratégico 2019-2022: educação para o século XXI (20I9), elaborado pela Secretaria de Educação do Estado de São Paulo, e, mais especificamente, do "Mapa estratégico 2019-2022", que se apresenta na página I5 do documento.

\section{O PLANO ESTRATÉGICO 2019-2022: UMA ANÁLISE DA ORGANIZAÇÃO DO TRABALHO DOCENTE E SUAS METAS}

Nesta seção apresentamos os resultados das análises que realizamos sobre o "Mapa estratégico 2019-2022", que está sendo amplamente divulgado nas escolas da rede escolar básica do estado de São Paulo pela Secretaria de Educação local. A análise procura tensionar a relação, indissociável, entre trabalho e educação no capitalismo contemporâneo, demonstrando que, assim como o mundo do trabalho, não por acaso a educação escolar básica também passa por um violento processo de ampliação dos mecanismos geradores de valor e, consequentemente, segue rumo à precarização.

As metas estratégicas, como o próprio nome já diz, seguem a forte tendência da flexibilização do trabalho definida por Antunes (2009), cujas análises foram objeto da segunda seção deste artigo. Para que os trabalhadores das escolas objetivem cumprir, ainda que apenas razoavelmente, os propósitos estipulados pelo Governo do Estado de São Paulo, devem dedicar-se mais intensamente, aumentando sua produtividade. Isso significa que o Plano estratégico 20I9-2022 do governo paulista contribui, por um lado, para a intensificação do trabalho dos professores nas instituições de ensino e, por outro, intensifica a precarização do trabalho docente, sob o manto da “inovação" ou do determinismo tecnológico a que já nos referimos anteriormente. Desse modo, os trabalhadores da área da educação sobrevivem de baixos salários, relações de trabalho precarizadas e da intensificação do trabalho por meio das metas determinadas pelo governo.

O "Mapa estratégico 20I9-2022" foi apresentado pelo Governo do Estado de São Paulo como uma parte do Plano estratégico 2019-2022: uma educação para o século XXI (doravante plano estratégico) com a justificativa de superar os desafios da rede pública estadual de educação de São Paulo. Esses desafios são, segundo o plano: I) o 
tamanho da rede de ensino pública paulista; 2) o preocupante desempenho do estado no Ideb e no Saresp; 3) problemas na gestão de pessoas, que incluem a "dificuldade de atrair e reter talentos, remunerar adequadamente e aumentar o número de professores que trabalham em uma única escola", além do absenteísmo dos professores; 4) problemas na gestão da rede de ensino, "efeitos da baixa eficiência operacional" e utilização deficiente dos recursos (SÃO PAULO, 20I9, p. I2-I3).

O mapa, por sua vez, contém a visão de futuro para 2022 e para 2030, a missão, os valores, os objetivos estratégicos, projetos prioritários e os fundamentos. Ele foi primeiramente apresentado na página I5 do Plano estratégico 20I9-2022 e sintetiza as resoluções da Secretaria Estadual de Educação para os problemas apontados. As 2I páginas seguintes discorrem mais detalhadamente sobre os objetivos expostos no mapa.

\section{Figura 1}

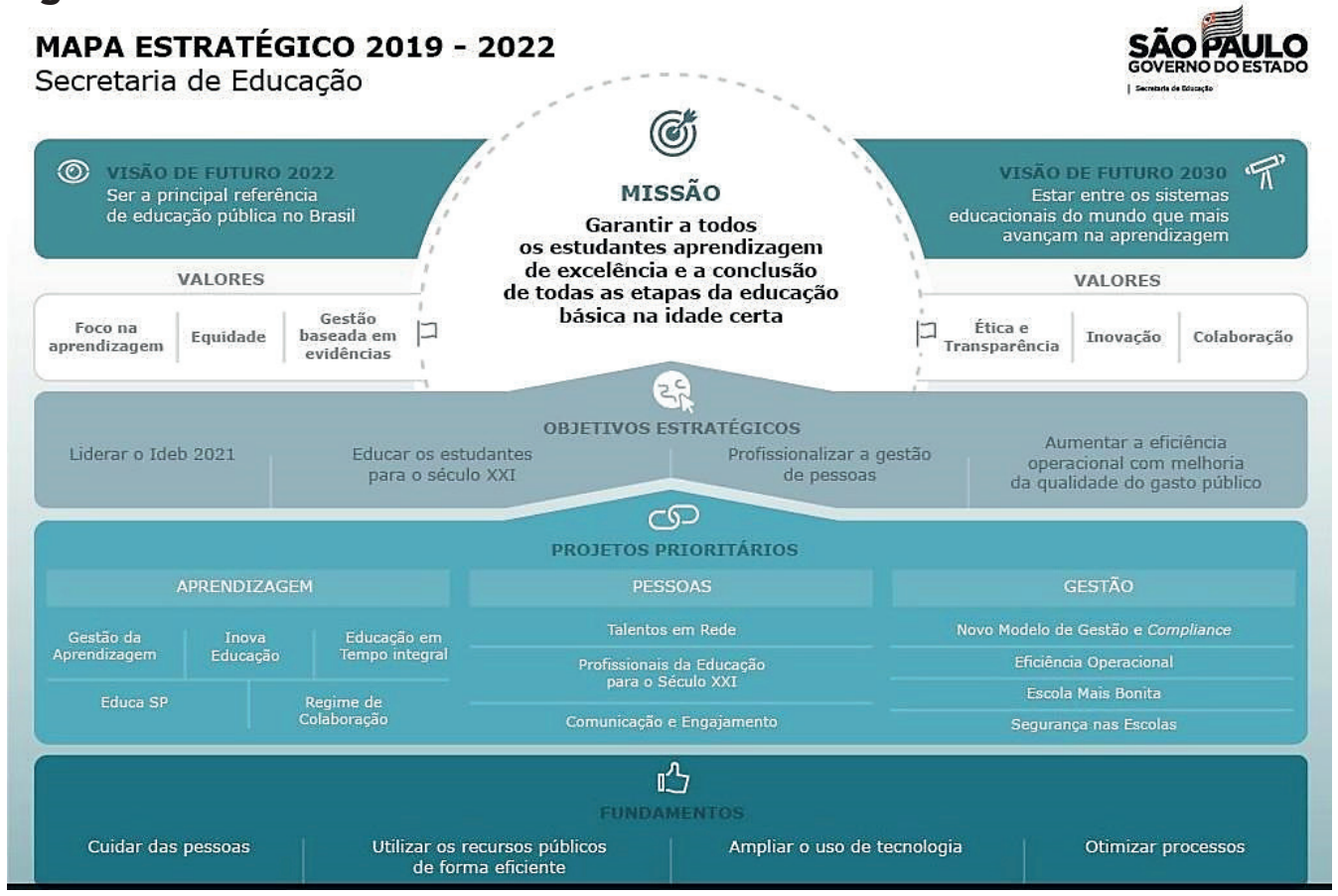

Fonte: Plano estratégico 2019-2022: uma educação para o século XXI.

A começar a análise do mapa pela missão, que é "garantir a todos os estudantes aprendizagem de excelência e a conclusão de todas as etapas da educação básica na idade certa", cabe pensar, em primeiro lugar, qual a função da educação que se pretende garantir aos alunos do ensino público paulista.

Segundo o plano estratégico, o ensino que deverá ser garantido é aquele que "ofertar uma educação que faça sentido para os estudantes, a fim de engajá-los e prepará-los para a vida e o mercado de trabalho", e, segundo o próprio mapa, dentre seus objetivos, "educar os estudantes para o século XXI" (SÃO PAULO, 20I9, p. II). Entretanto, se pensamos a educação escolar como aquela que tem o objetivo social de humanizar 
os indivíduos por meio da socialização dos conhecimentos historicamente produzidos e acumulados pela humanidade, torna-se imprópria a redução da função social da educação escolar como propositada a "preparar para o mercado de trabalho", ou então "garantir a conclusão de todas as etapas da educação básica na idade certa”.

Como garantir uma “aprendizagem de excelência” se a missão também é cumprir os prazos da conclusão na idade certa? Como engajar os estudantes e prepará-los para a vida concedendo a eles uma educação escolar que prioriza uma formação que atenda às exigências do mercado de trabalho? Essas são contradições que impossibilitam uma educação escolar básica que de fato contribua para o processo de humanização dos que a ela têm acesso.

Em seguida, o mapa apresenta algumas noções de "valores" que se traduzem em conteúdos morais e estratégias de controle comportamental, tais como "virtudes e características que norteiam o trabalho das equipes, estabelecem limites e orientam atitudes e comportamentos" (SÃO PAULO, 20I9, p. I7). No entanto, e ironicamente, se relacionam com a ampliação dos mecanismos de extração de mais-valor (ANTUNES, 20I8, p. I64).

A colaboração e a inovação, principalmente, exigem que os assalariados públicos das escolas trabalhem com base em um cooperativismo voluntário, devendo, portanto, "gerar soluções em conjunto, trabalhar em equipe de forma integrada, respeitando a contribuição de todos e colaborando em torno de objetivos e metas comuns", além de serem proativos "para buscar oportunidades e soluções criativas para problemas, buscando impactar positivamente a rede estadual e a aprendizagem dos estudantes" (SÃO PAULO, 2019, p. I7).

Nesse sentido, partindo de análises rigorosas do mapa, fica evidente que os docentes devem fazer parte da escola não apenas de uma maneira remunerada, coletiva, com intenção pedagógica e integrada, mas, na verdade, como em uma empresa, também devem acatar exigências, cumprir metas e assegurar o desenvolvimento das competências e habilidades exigidas pelo mercado capitalista.

A noção empreendedora de proatividade e criatividade implica, na rede pública e privada, a intenção de explorar em maior grau o trabalho dos funcionários e alunos, com objetivos que não deveriam ser os de uma educação escolar de qualidade socialmente referenciada. Aumenta-se, portanto, o trabalho abstrato e os mecanismos geradores de valor dentro dessas instituições, modificando os reais sentidos do trabalho humano, como escreveu Antunes (2018, p. 26):

Quando a vida humana se resume exclusivamente ao trabalho - como muitas vezes ocorre no mundo capitalista e em sua sociedade do trabalho abstrato - , ela se converte em um mundo penoso, alienante, aprisionado e unilateralizado. É aqui que emerge uma constatação central: se por um lado necessitamos do trabalho humano e de seu potencial emancipador e transformador, por outro devemos recusar o trabalho que explora, aliena e infelicita o ser social, tal como o conhecemos sob a vigência e o comando do trabalho abstrato. 


\section{A flexibilização do trabalho, nessa nova} organização das relações capitalistas de produção, não é sinônimo de riqueza, tampouco de mais horas extras para desenvolver outras atividades laborais ou até mesmo de facilidade de ser admitido. A flexibilização, por parte do elo mais frágil, o detentor da força de trabalho, é caracterizada como ausência de garantias, que acaba aumentando a vulnerabilidade e intensificando o fator de risco mais importante para o trabalhador: o desemprego

Se por um lado os professores devem trabalhar voluntariamente de acordo com esses princípios, que são por muitos avaliados como "avanços", os alunos, por outro, devem se focalizar em cumpri-los satisfatoriamente, não como sujeitos particulares e distintos que são, mas sim como máquinas programadas para responder a comandos.

Além disso, as duas visões de futuro apresentadas têm como meta o desenvolvimento nos índices avaliativos que a escola pública apresenta nas provas nacionais e internacionais; portanto, a meta de estar bem ranqueada nas avaliações continua a prevalecer no mapa e no plano estratégico. Dentre os que são intitulados objetivos estratégicos, o primeiro diz respeito a liderar o Ideb.

O Ideb (Índice de Desenvolvimento da Educação Básica) consiste em um cálculo do indicador do fluxo escolar juntamente com as médias de desempenho nas avaliações (Censo Escolar, Saeb e Prova Brasil). Portanto, o objetivo do mapa estratégico expressa a valorização do ranqueamento, em termos quantitativos, dos dados relacionados à educação. O que significa que as escolas públicas do estado de São Paulo devem estabelecer como meta atingir bons números para cumprir essa exigência e, consequentemente, estabelecer um sistema pautado na competição. O Ideb exige resultados dos professores e estudantes, os quais devem reconfigurar o funcionamento e a vivência da escola para alcançar exclusivamente os números desejados, ou melhor, como diz o próprio objetivo, liderar. 
A meta soa, inclusive, incompatível com um dos valores apresentados no plano estratégico, que diz que o trabalho dos profissionais da educação deve:

Pautar-se pelo princípio da equidade no tratamento das diferenças regionais, locais, entre escolas e estudantes, oferecendo tratamentos diferenciados de acordo com as necessidades específicas, a fim de promover efetiva igualdade de oportunidades (SÃO PAULO, 2019, p. 17).

Nessa perspectiva, se os estudantes possuem diferentes necessidades, possuem também reações distintas aos processos de ensino e aprendizagem, que não podem ser reduzidas a resultados avaliativos, principalmente quantitativos, extraídos de exames idênticos.

Assim sendo, a meta estipulada é potencialmente inalcançável com base na realidade dos sujeitos que compõem a escola, e, com isso, condiciona os profissionais da educação a buscar em seu trabalho uma homogeneização das práticas e dos resultados inexecutável. Ou seja, devido ao interesse capitalista e neoliberal por ranqueamentos, que para a educação deveriam ser banais, as escolas tendem a caminhar rumo ao fracasso e à precarização, pois, em realidade, não podem e não conseguem coincidir com esses objetivos.

No livro O privilégio da servidão: o novo proletariado de serviços na era digital (20I8), o autor, Ricardo Antunes, ao falar dos adoecimentos do trabalho, escreve a respeito da gestão por metas, como um dos mecanismos de exploração do trabalho, utilizado para aumentar a produtividade e o disciplinamento do trabalho:

Dessa forma, o gerenciamento por metas opera em diferentes sentidos: a) no desenvolvimento de mais um mecanismo disciplinador do trabalho, como na instituição de uma espécie de engajamento "voluntário" dos trabalhadores e trabalhadoras visando ao aumento da produtividade; b) no incentivo ao controle de faltas exercido, não raro, entre os próprios membros dos times de produção/equipes de trabalho; c) na diminuição do tempo de repouso; d) na promoção da competição entre os trabalhadores e suas equipes, visando ao recebimento dos valores estipulados nos acordos firmados para essa finalidade; e) no aprofundamento das experiências de acordos coletivos firmados por empresas (ANTUNES, 20I8, p.I47).

A passagem acima nos permite identificar que os princípios de gestão empresarial seguem metas que têm como objetivo principal o disciplinamento e o controle dos trabalhadores. Se observarmos as metas e objetivos propostos pelo plano estratégico da educação escolar para o estado de São Paulo, constataremos a indissociabilidade a que nos referimos entre as determinações do mundo do trabalho e as políticas educacionais. Vale salientar que um dos passos para alcançar uma educação de melhor qualidade é a implementação de objetivos, visando atingi-los gradualmente através de, por exemplo, formação continuada de professores, desenvolvimento 
de projetos político-pedagógicos com maior ênfase no desenvolvimento pautado na emancipação humana, gestão democrática etc. No entanto, o mapa não traça objetivos com rigor e intencionalidade pedagógica, mas sim visando ao desenvolvimento da instituição escolar como uma empresa e impondo-lhe metas, como já abordado anteriormente.

O Governo do Estado de São Paulo deveria, para projetar uma educação escolar transformadora, agir, primeiramente, na contramão do mercado e dos imperativos neoliberais, priorizando estratégias fundamentadas nos estudos direcionados à educação e às políticas educacionais, respeitando o tempo, a dedicação de trabalho e a remuneração dos trabalhadores da rede e considerando também as realidades subjetivas daqueles que compõem a escola. O planejamento da educação não pode ser reduzido a metas dissimuladas, descontextualizadas da realidade, que precarizam o trabalho e iludem os objetivos fundamentais da educação como prática social.

São essas, portanto, evidências que indicam o caminho da educação rumo a sua mercantilização. Ou seja, a educação escolar passa a assumir um papel estratégico no sentido de adaptar o trabalhador às demandas do mundo do trabalho, contribuindo para o desenvolvimento do consenso social, a que nos referimos anteriormente, de que o mercado é o único e inevitável caminho para o progresso dos indivíduos e, consequentemente, da sociedade. É preciso formar cidadãos empreendedores para um mercado de trabalho sem direitos, informal, precarizado, isto é, formar trabalhadores que se convençam de que são livres dos patrões, tornando-os déspotas de si mesmos, os chamados "pejotizados", conforme esclarece Antunes (20I8).

Outro item presente nos "objetivos estratégicos" do mapa é a noção de profissionalizar a gestão de pessoas. Segundo o plano estratégico, "profissionalizar a gestão de pessoas é condição para que a secretaria consiga alcançar melhores resultados" e, para que isso aconteça, ainda segundo o plano, é necessário que esteja envolvida uma série de "elementos, entre eles avaliação e seleção de pessoas por competências, formação e desenvolvimento profissional, modelo de remuneração atrativo, criação de incentivos meritocráticos, comunicação e engajamento" (SÃO PAULO, 20I9, p.I8).

Quando o plano estratégico apresenta a gestão de pessoas e, juntamente com ela, conceitos como seleção de pessoas por competências e incentivos meritocráticos, deixa claras, também, a individualização e a solidão do profissional. Além disso, por colocar os profissionais em um ambiente de competição, no qual aquele que se dedicar mais e obtiver melhores resultados receberá uma remuneração mais atrativa, também rompe com as relações de solidariedade entre os trabalhadores. Nesse sentido, Antunes (20I8, p. I5I), nos lembra que:

O rompimento das noções de solidariedade entre os trabalhadores e, somado a isso, a solidão e a individualização, são instrumentos para um desmonte da classe trabalhadora, a partir do qual esses trabalhadores deixam de se enxergar como pertencentes à classe, distanciando-se, portanto, da organização que barra desmontes nos direitos trabalhistas. 


\section{O capital, por meio da difusão de um novo léxico, contribui, de fato, para a construção de um novo senso comum, o qual é divulgado por meio dos documentos que passaram a regulamentar a reforma educacional iniciada na década de 1990 e que hoje se consolida}

Também vale ressaltar que a Secretaria da Educação do Estado de São Paulo, ao superestimar a gestão de pessoas, entrega aos funcionários da escola a responsabilidade pelo sucesso escolar, já que, para que haja maior remuneração, devem-se aumentar também as notas nas avaliações, e, para isso, esses funcionários precisam estar mais "engajados", isto é, precisam ser mais produtivos para o capitalismo.

Essa estratégia de envolvimento dos trabalhadores da escola com os resultados das avaliações demonstra outro aspecto das estratégias de disciplinamento dos trabalhadores na atualidade que é incorporado pelas políticas educacionais. Sobre esse aspecto, Antunes (20I8) lança luz sobre as diferentes formas de absorção das energias humanas e da subjetividade do trabalhador, que acabam interiorizando a lógica competitiva entre os pares em detrimento das relações de solidariedade a que nos referimos anteriormente.

Trata-se, segundo Antunes (20I8), de estratégias que promovem a intensificação da alienação do trabalhador em relação ao resultado do seu trabalho e em relação ao outro. Ele é convocado, cotidianamente, a internalizar a função de gestor de si mesmo e passa a desenvolver o autocontrole do seu trabalho e do trabalho alheio. Nesse sentido, o autor esclarece que:

Se, na empresa taylorista-fordista, o despotismo é mais explícito em sua conformação, e o estranhamento ou o modo de ser da coisificação acaba sendo mais "direto", na fábrica da flexibilidade liofilizada, diferentemente, as novas técnicas de "gestão de pessoas", as "colaborações" e as "parcerias" procuram "envolver" as personificações do trabalho de modo mais interiorizado, procurando converter os empregados "voluntariamente" em uma espécie de autocontroladores de sua produção, em déspotas de si mesmos (ANTUNES, 20I8, p. I09,grifos nossos).

O último objetivo estratégico se centra em "aumentar a eficiência operacional com melhoria da qualidade do gasto público" (SÃO PAULO, 20I9, p. I8). Esse objetivo volta a aparecer entre os fundamentos do mapa, em utilizar os recursos públicos de forma 
eficiente; segundo o plano estratégico, isso se dará mediante a realização do compromisso de:

Fazer mais, gastando menos e zelando pelos recursos públicos, utilizar os recursos públicos de forma mais efetiva, alinhando a alocação de recursos ao plano estratégico para que sejam destinados conforme as prioridades e de maneira eficiente, para que os resultados almejados sejam alcançados (SÃO PAULO, 2019, p. 36).

O que é possível perceber na citação do plano estratégico é que, mais uma vez, a responsabilidade de garantir a educação almejada pelo governo do estado é entregue aos professores e trabalhadores da escola pública, permitindo que o próprio governo se retire da responsabilidade do envio de verbas, que é fundamental para a manutenção da escola e, consequentemente, para o ensino de qualidade. Com isso, aumenta-se a intensidade do trabalho desses profissionais e se os coloca em situação de assédio, recusando-lhes salários e jornadas dignas de trabalho.

Antunes (2018) afirma que tal ação é parte do processo de modernização de empresas diante das mudanças do sistema capitalista, portanto não se trata de uma ação que visa à humanização dos alunos (e dos professores) pelo ensino, mas sim da implementação de uma das engrenagens do funcionamento dessas empresas no sistema capitalista.

O trabalho em equipe, a transferência das responsabilidades de elaboração, anteriormente realizada pela gerência científica e agora interiorizada na própria ação dos trabalhadores - um dos traços do management by stress-, são outras marcas fortes presentes nessa processualidade (ANTUNES, 20I8, p. I04).

De acordo com as análises propostas, é possível identificar um projeto para a educação básica brasileira que avança no sentido da sua mercantilização e consoante as exigências do capital mundializado, portanto um projeto que aplica, progressivamente, os mecanismos de intensificação do trabalho e da ausência de direitos. Esse projeto coloca em risco a noção de educação humanizadora, pondo a escola pública a serviço da manutenção da desigualdade de classes e do desmonte da classe trabalhadora de professores. As metas, as colaborações, as inovações, a gestão de pessoas e os valores, entre outros itens do mapa estratégico, indicam, juntamente com a nova morfologia do trabalho, que:

Ao contrário da retração ou descompensação da lei do valor, o mundo contemporâneo vem assistindo a uma significativa ampliação de seus mecanismos de funcionamento, no qual o papel desempenhado pelo trabalho - ou o que venho denominando a nova morfologia do trabalho - é emblemático (ANTUNES, 20I8, p. 66). 
Essa ampliação dos mecanismos de extração do sobretrabalho não se restringe à esfera privada, como demonstramos neste estudo. Ela se expande também, muito severamente, nos espaços públicos, e na educação se manifesta como um projeto estruturado e articulado para tal. Há que existir muita atenção daqueles que são professores e dos que defendem a educação pública de qualidade para que esta não continue a ser mercantilizada e para que não deixe de estar a serviço dos filhos da classe trabalhadora e passe a servir aos interesses das empresas capitalistas.

\section{CONSIDERAÇÕES FINAIS}

Após os resultados da pesquisa que apresentamos neste artigo, consideramos que a chamada globalização da economia consiste, ao contrário do que esse conceito indica, no processo de mundialização do capital, conforme demonstramos na primeira seção destes escritos. Ou seja, trata-se de uma ideologia que tem por objetivo ocultar a essência das relações sociais capitalistas por meio das estratégias de reestruturação do capital, que visam garantir o lucro e a acumulação ampliada. Observamos ainda que tais estratégias, para ser consolidadas, precisam de um novo consenso social e, nesse sentido, verificamos que a educação ocupa lugar estratégico na construção desse consenso. Portanto, consideramos que o capital, por meio da difusão de um novo léxico, contribui, de fato, para a construção de um novo senso comum, o qual é divulgado por meio dos documentos que passaram a regulamentar a reforma educacional iniciada na década de 1990 e que hoje se consolida. Portanto, consideramos que sob o manto da ideologia do determinismo tecnológico difundem-se, por meio da educação, as necessidades técnicas e ideológicas do capitalismo contemporâneo. Desse modo, podemos afirmar que essa ideologia promove a intensificação dos mecanismos de extração de valor e, consequentemente, a ampliação da riqueza dos proprietários dos meios de produção.

Com relação à nova morfologia do trabalho, tratada na segunda seção deste artigo, constatamos, a partir dos estudos realizados, que se trata de novas tendências que se consolidam no contexto do capitalismo contemporâneo. Nomeadamente, a assim chamada flexibilização do trabalho, conceito que passou a fazer parte do novo léxico empresarial, o qual, analisado em sua essência, corresponde de fato a novas tendências que promovem a precarização do trabalho e o desemprego, destituindo a classe trabalhadora dos direitos trabalhistas e sociais historicamente conquistados. Portanto, o processo de reestruturação produtiva, que contribuiu para o desenvolvimento dessa nova morfologia do trabalho, explicita as contradições inerentes ao modo de produção capitalista. Ou seja, por um lado, esses fenômenos associados garantem aos capitalistas a ampliação dos lucros e da acumulação, e, por outro, para os trabalhadores, resta a perda de direitos advinda da flexibilização: mais trabalho com "metas" e "colaborações", mais horas de dedicação, menos direitos, e salários precarizados. 
Na terceira parte, apresentamos os resultados das análises do mapa estratégico presente no Plano estratégico 2019-2022 do Governo do Estado de São Paulo. Observamos aí uma forte política de gestão da escola pública que pretende seguir essa nova morfologia do trabalho: mercantilizando a educação, retirando dela o caráter humanizador e colocando-a a serviço do sistema capitalista, como uma empresa que prioriza seus lucros e assedia a categoria dos trabalhadores. Portanto, o Governo do Estado de São Paulo mobiliza e organiza seus professores para que definitivamente trabalhem em busca das metas definidas pelo plano estratégico, alienando-os do caráter humanizador do seu trabalho e favorecendo o rompimento do tecido de solidariedade que mantém a noção de classe trabalhadora.

Desse modo, é possível considerar que os resultados da pesquisa demonstraram, sim, que a nova morfologia do trabalho atinge os trabalhadores da educação escolar, desenvolvendo neles a necessidade de trabalhar sempre a favor da manutenção do capitalismo, bem como no favorecimento do seu desenvolvimento e de sua inserção em campos que pelo menos até então se acreditava serem de difícil acesso, como por exemplo nas escolas públicas.

Em síntese, o processo de mundialização do capital em curso, a reestruturação produtiva e a nova morfologia do trabalho decorrente dessa última são fenômenos que exercem grande influência na tomada de decisões e no desenvolvimento de políticas educacionais, bem como nas políticas que regulamentam o trabalho do professor na educação escolar, conforme pudemos observar a partir da análise do Plano estratégico 2019-2022 do governo paulista, cujos dados não esgotam o tema, mas podem ser tomados como exemplo do processo de precarização do trabalho do professor. Assim, finalizamos esse artigo respondendo à pergunta anunciada em seu título: A nova morfologia do trabalho influencia o trabalho do professor na educação escolar pública? Nossa resposta é sim, tendo em vista que o plano estratégico do Governo do Estado de São Paulo propõe como desafio para resolver as mazelas da escola pública, por ele criadas, um plano de gestão educacional fundamentado na lógica da gestão empresarial. Resta, portanto, aos trabalhadores da educação pública do estado de São Paulo e do país em sua totalidade, resgatar o espírito de solidariedade classista como antídoto à lógica produtivista, competitiva e individualista a que estão submetidos.

* Mestrando em Educação pela Universidade Federal de São Carlos (Ufscar).

E-mail: brenoblundi@outlook.com

**Graduada em Licenciatura em Letras pelo Instituto de Biociências, Letras e Ciências

Exatas da Universidade Estadual Paulista(Ibilce/Unesp). E-mail: turativitoria@gmail.com

***Graduada em Licenciatura em Letras, Instituto de Biociências, Letras e Ciências

Exatas da Universidade Estadual Paulista (Ibilce/Unesp).

E-mail: giovannacandeira@gmail.com

Texto recebido em maio de 2020; aprovado em maio de 2020. 
ANTUNES, R. Adeus ao trabalho? ensaio sobre as metamorfoses e a centralidade do mundo do trabalho. São Paulo: Cortez, 1995.

ANTUNES, R. O caracol e sua concha: ensaios sobre a nova morfologia do trabalho. São Paulo: Boitempo, 2005.

ANTUNES, R. O privilégio da servidão: o novo proletariado de serviços na era digital. São Paulo: Boitempo, 2018.

ANTUNES, R. O trabalho, sua nova morfologia e a era da precarização estrutural. Revista Theomai, n. 19,jan./jun. 2009. Disponível em: <http://revista-theomai.unq.edu.ar/ NUMERO19/ArtAntunes.pdf>. Acesso em: 20 abr. 2020.

ANTUNES, R. Os sentidos do trabalho. São Paulo: Boitempo, 1999.

AZEVEDO, M. L. N. A integração dos sistemas de educação superior na Europa: de Roma a Bolonha ou da integração econômica à integração acadêmica. In: SILVA JR., João dos Reis; OLIVEIRA, João Ferreira; MANCEBO, Deise (Org.). Reforma universitária: dimensões e perspectivas. Campinas: Alínea, 2006.

CHESNAIS, F. A mundialização do capital. São Paulo: Xamã, 1996.

DALE, R. Globalização e educação: demonstrando a existência de uma "cultura educacional mundial comum" ou localizando uma "agenda globalmente estruturada para a educação"?. Educação, Sociedade \& Cultura, n.16. Porto: Afrontamento, 2001.

DOURADO, L. F. Políticas e gestão da educação superior a distância: novos marcos regulatórios?. Educação e Sociedade, Campinas, v. 29, n. 104, especial, p. 891-917, out. 2008.

FERREIRA, S. A universidade do século XXI: concepções, finalidades e contradições.

2009. Tese (Doutorado), Universidade Federal de Goiás, Goiânia, 2009.

GERMANO, J. W. Globalização contra-hegemônica, solidariedade e emancipação social.

Cronos, Natal, v. 8, n. 1, p. 41-55, jan./jun. 2007. Disponível em: <https://webcache. googleusercontent.com/search?q=cache:X3UalaG38JwJ:https://periodicos.ufrn.br/cronos/ article/download $/ 3167 / 2557 /+\& c d=1 \&$ hl=pt-BR\&ct=clnk\&gl=br $>$.Acesso em: 20 abr. 2020. 
GONÇALVES, M. E. Europeização e direitos dos cidadãos. In: SANTOS, B. S. (Org.). Globalização: fatalidade ou utopia?. 3. ed. Porto: Afrontamento, 2005.

LIMA, K. Contrarreforma na educação superior: de FHC a Lula. São Paulo: Xamã, 2007.

PUREZA, J. M. Para um internacionalismo pós-vestefaliano. In: SANTOS, B. S. (Org.).

Globalização: fatalidade ou utopia?. 3. ed. Porto: Afrontamento, 2005.

SANTOS, B. S. Introdução geral à coleção. In: (Org.). Democratizar a democracia: os caminhos da democracia participativa. Rio de Janeiro: Civilização Brasileira, 2002.

Os processos de globalização. In: . (Org.). Globalização: fatalidade ou utopia?. 3. ed. Porto: Afrontamento, 2005.

SÃO PAULO (Estado). Secretaria de Educação. Plano estratégico 2019-2022: educação para o século XXI. São Paulo: Secretaria de Educação, 2019. Disponível em: <https://www. educacao.sp.gov.br/wp-content/uploads/2019/07/plano-estrategico2019-2022-seduc compressed.pdf>. Acesso em: 1 jun. 2020.

STOER, S. Educação e globalização: entre regulação e emancipação. Revista Crítica de Ciências Sociais. Coimbra, n. 63,p. 33-45, 2002.

OSIKE, D. P. Relativismo linguístico em 1984 de George Orwell.2011. Trabalho apresentado como requisito parcial para aprovação na disciplina Orientação Monográfica II, Setor de Ciências Humanas, Letras e Artes, Universidade Federal do Paraná, Curitiba, 2011. VASAPOLLO, L.: O trabalho atípico e a precariedade. São Paulo: Expressão Popular, 2005.

; ARRIOLA. J. L'uomo precário nel disordine globale. Milão: Jaca Book, 2005. 